\title{
Learning and Teaching Opportunities of Ethnic Minorities in Multicultural China. Unity, Diversity or Critical Pluralism?
}

\section{KEYWORDS}

minority education, China, school in China, religion, language, minzu

\begin{abstract}
This article explores current issues of minority education in China, especially in the context of religion and language education. In the first part of the article, the author describes (1) cultural and political framework of Chinese education in general and (2) current educational conditions, also discussing differences in educational attainment for minority groups in China. The second part of the article presents the situation of minority religions, which is not really recognised in state schooling in China. The author shows educational examples from the Tibet region and from Muslim education. The third part of the article explores another major challenge related to ethnic minority schooling, which is language diversity. In the final part of the paper, the author tries to comment on Chinese minority education dilemmas and concludes with some social recommendations.
\end{abstract}

Adam Mickiewicz University Press, pp. 69-81

ISSN 2300-0422. DOI 10.14746/kse.2019.15.5

ORCID: https://orcid.org/0000-0003-1026-9487

The case of multiculturalism of China is very specific and uneasy to explore. China has a rich, centuries-old and complex multicultural tradition, which currently additionally struggles with market forces. In the subject literature concerning education of ethnic minorities of the Middle Kingdom we may read that the country primarily promotes itself as a harmonious, multicultural mosaic, where as many as 56 distinct ethnic groups (in Chinese referred to as minz $u^{1}$ ), officially approved

\footnotetext{
${ }^{1}$ In the text I am going to use this designation interchangeably, having in mind ethnic groups.
} 
of and defined by the state apparatus in 1950s and 1960s, ${ }^{2}$ strive towards shared, peaceful coexistence. James Leibold and Chen Yangbin (2014) note that the Chinese ethnic mosaic is exceptional in its structure, because as much as $92 \%$ of it belongs to Han people. The people of Han constitute the meta majority of China's population, and the common (official) characteristic feature connecting the group is the written language. The remaining $8 \%$ belongs to the defined and accepted ethnic minorities (Leibold, 2013).

It is worth noting that multiculturalism of China is two-faceted. On the one hand, the Middle Kingdom is an interesting, intriguing country, where theoretically the abovementioned minzu live in accordance with the assumptions of the state apparatus. On the other hand, through its century-long diversity, China is becoming a complicated country, sometimes even dangerous. Internal Chinese conflicts, or episodes of hatred, such as the outburst of aggression towards the ethnic minority in the town of Lhasa in 2008 or Shaoguan in 2009, constant quest for territorial and cultural separation of Mongols and Uyghurs, or persecutions of Christians (particularly in Guangdong and Junnan provinces), show that China struggles with similar problems as other multicultural countries, however their scale and frequency are proportionally bigger and more common. Additionally, the issue is hindered by the fact that ethnic relations in China are subject to regulations of policies and legal resolutions which aim at maintaining the autonomy of the abovementioned 56 groups, while simultaneously sustaining the national unity (in the social and cultural sense).

Gerard Postiglione (1998) claims that the educational system of China is one of the tools of supporting this goal. By its means, the Middle Kingdom tries to minimise the internal tensions and promote multicultural harmony. Implemented educational solutions aim at mitigating the effects of internal pluralism; therefore, Chinese schools face an exceptionally difficult task. On the one hand, the schools are to reproduce the national (Chinese) culture and constitute a "brand of national culture" (zhongua minzu wenhua) in China (Postiglione, 1998). Following the idea of the abovementioned author, it might be claimed that state apparati do their best to prevent school from using unbeneficial, adverse (unaccepted by the state) cultural influences, originating for instance in the Western culture. On the other hand, state schools are also responsible for the protection and propagation of culture, religion and language of minorities. The aim of this article is to de-

\footnotetext{
${ }^{2}$ In 1950s and 1960s, the Chinese government employed a team of scientists, mainly anthropologists, whose task was to describe the ethnic minorities in China. Initially, Chinese citizens reported as many as 400 various identities. The task of the scientists was to check these claims. Consequently, 56 minority groups were defined and approved.
} 
scribe Chinese educational reality in the multicultural society. A question should be asked whether the contemporary system of Chinese education corresponds to the needs of multicultural society and what kind of practices and educational solutions are applied in the case of students from ethnic minorities, particularly in the case of teaching the language and religion and whether applied educational practices affect the school enrolment rate. In the text I am going to focus primarily on educational solutions applied from the early years of education until the end of the second-degree middle school. ${ }^{3}$ Research materials to this work are taken from existing research on multicultural education in China, both of local (Chinese) and foreign (mainly American) authors. The analytical problems result from the scope and range of Chinese multiculturalism; therefore, the analysed issue can be considered as difficult to recognise.

\section{Cultural Educational Framework}

When writing about the education of minorities in China, it is necessary to mention complicated philosophical and religious Chinese cosmology, in which the applied educational solutions are deeply rooted. Baogang He (1998) assumes that the Confucian tradition best explains the rules of common life applicable in contemporary multicultural China. Confucian communitarianism, by means of paternalistic solutions used for harmonious coexistence of culturally adverse minorities, by assumption is to support and protect this minzu diversity (He, 1998). Other than, for instance, in Western liberalism, in Confucian tradition the phenomena of individualism, group distinctiveness or individual rights do not exist.

To show the paradox, it is also worthwhile to refer to Confucian culturalism, which in its nature assumes a certain hierarchy: the Chinese Xia (meaning orthodox, central, civic, Chinese) and Yi (peripheral, heterodox, non-Chinese) are put on opposing poles. Xia is responsible for upholding the order and stability, and defines also what is proper (applicable, desirable) for Yi. According to Chinese Confucianism, all inhabitants of the Chinese land should aim at adopting the Xia norms. Therefore, the members of minority groups, including students, according to Confucian assumptions, are expected to be faithful and loyal to the country. Furthermore, the existing social values and norms are regulated by a complicated

\footnotetext{
${ }^{3}$ In another article, A. Mańkowska Linguistic educational reality in multicultural China. Unity or diversity? (Językowa rzeczywistość edukacyjna w wielokulturowych Chinach. Jedność czy różnorodność?) "Pedagogika Szkoły Wyższej”, 2018, 2/2017 (22), pp. 121-132, DOI: 10.18276/psw.2017.2-11, educational practices including higher education were described.
} 
political system. After 1949, for instance, China changed the manner of perceiving minorities in the country. Using a descriptive language, it might be said that Confucian assumptions were additionally given a Marxist-Leninist framework. According to James Leibold (2013), ethnic policy in China has been since that time deeply rooted in this framework and despite social and political changes it still remains in it. For minorities, it means new social rules and principles. For instance, in Mao Zedong times (along with the Communist Party of China) several political actions were undertaken towards the minorities. First of all, the 56 groups of ethnic minorities mentioned before were officially defined. Territories of place of residence of the minorities were separated, and new, preferential rights (privileges) were established for education, employment and procreation, which were additionally strengthened in 1980s and are still applicable.

It is also interesting that the idea of community has always been present in the Chinese doctrine, and a specific cultural unity has been a dominating factor legitimising the Chinese political ideology. The traditional ideology of common harmony (datong), in other words "great community," was supposed to serve to maintain the Chinese social unity. In policy, also educational, there was a frequent reference to the cultural immunity of "Heavenly mandate" (dominance of Chinese culture and centralised system of control), however according to the data provided by Postiglione (1998), contemporary criteria of adjustment of educational practices and policy for the minorities depend on a number of factors. The most important of them include: the population of the minority, group identification character; size, place and location of the settled area; maintained relations with other ethnic groups; prevalence of rural or urban origin people; area population; whether the group has strong religious traditions or not; whether the group has the distinct written language apart from the spoken one; what is the dispersion of group members around the country and whether the group has its own traditions of establishing intercultural relations.

In order to treat all minzu equally, by assumption the educational system is constructed in such a way as to treat differently all particular minority groups. There are two types of education in China: for students from the Han minority (i.e. majority), the so-called standard education (zhenggui jiaoyu), and special education for the remaining groups, the so-called ethnic education (minzu jiaoyu) (Postiglione, 1998).

It is worthwhile to refer here to remarks of Catrion Bass, who claims that the Chinese educational system has always been far from coherent and its structure has been marked by social stratification. According to the researcher, Han people were educated in a way which was to provide the country with personnel necessary 
to achieve the economic development, whereas the main educational goal for the remaining minzu was to maintain the political and cultural loyalty of students to the country (Bass, 1998). Warren Smith's conclusions are similar. He writes that the development of the Chinese state is characterised by dominance, and ideology of common harmony is frequently used in the political dialogue. Common harmony is maintained by means of the centralised system of control and ubiquitous dominance of Chinese culture, also by means of the educational system (Smith, 2009). It is contrary to one of the global phenomena intensifying recently among the minority groups, which is based on strengthening their own, ethnic identity, particularly in countries with rich multicultural tradition. In China, despite existing national and cultural framework, the aspirations to cultural independence are exceptionally strong, particularly in Tibet and Sinciang province, where local ethnic groups have for years been struggling to upkeep their own identity at two levels, of religion and language. Therefore, it is worth taking a look at what educational practices and solutions are applied to ethnic minorities, particularly in the matter of teaching language and religion.

\section{Local, National or no Religion in the School System?}

Postiglione (1998) claims that practicing religion is widespread among Chinese minorities, and the social changes taking place, the modernisation of the country and the moral crisis plaguing China additionally stimulate religious interest of citizens. A similar phenomenon can be observed in other countries, such as the USA. An example of China shows, too, that the intensified involvement in the matters of faith and religion of particular minority groups can be extremely diversified. Among all the minzu, Han people are the group demonstrating the least religious involvement (Postiglione, 1998).

The dominating religions in China include Islam, Buddhism, Lamaism and Taoism. Some groups practice shamanism, polytheism, totemism, as well as the veneration of the dead. Few Christians are present among the Korean people, Miao or Yi (Mackerras, 1999). The most up-to-date research, conducted by the organisation Freedom House (Albert, 2018), showed that in China there are 350 million of religious followers, mainly Chinese Buddhists, Protestants, Muslims, Falun Gong followers, Catholics and Tibetan monks. It needs to be added that the government officially accepts five religious groups: Buddhism, Taoism, Islam, Protestantism and Catholicism. I would like to mention also that Chinese minorities are mostly characterised by rich religious traditions, which provide the abovementioned 
groups with a strong sense of own identity. Religious beliefs and practices have never been banned in China and the Constitution of the People's Republic of China (2004) declares the guarantee of the freedom of faith. In the Middle Kingdom we can find, however, examples of uneven treatment in the religious context, such as, for instance, financial support of the chosen religious groups by the country, particularly in areas which are attractive for tourists. Currently, the Chinese government indirectly controls the religious situation in the country, among others by means of specific state subsidies for the development of registered religious associations, liquidation of unregistered religious associations and creating the system of "patriotic churches." Nonetheless, official directives claim that the government does not interfere in the religious matters of minorities as long as they do not threat the matters of China (and mainly the Chinese unity) (Mackerras, 1999). Interestingly, the educational system by assumption should remain free of religious influences.

In accordance with the assumptions of the state school system in China, all students, also those from minorities (along with the autonomous regions), should follow the completely secularised system of education. Colin Mackerras (1999) claims that in formal school education in China, implemented in accordance with the national curriculum, there is no place for propagating any religious beliefs or practices. There are, however, certain exceptions. For instance, in language schools teachers can use Quran to teach Arabic, however the classes should not exceed the religious limits of learning. There are no formal counter indications for Tibetan monks and other priests to teach in state schools; however, their attire, behaviour or beliefs cannot demonstrate the religious context. According to Colin Mackerras (1999), while he was conducting research on religious practices in schools, he did not meet any clergyman working as a teacher. Most commonly, monks and clergymen work in monasteries, where they teach young boys (for instance in Tibet). Monasteries are not subjected to the school system, but they have an educational function: they are often referred to as "religious universities." The conclusion of research of Dru C. Gladney (1996) is that mosques and monasteries functioning as such are a direct cause of lower school enrolment rate. Gladney (1996), in his ethnographic studies on Hui people (Muslims) demonstrated that some parents, particularly from rural areas, did not feel the need to educate children in the state school and had them educated in mosques only. Social understanding of religious

\footnotetext{
${ }^{4}$ These are churches or institutions approved of/accredited by the Chinese government, cooperating with it at various levels.

${ }_{5}$ The function Buddhist monasteries or Muslim mosques is very peculiar in China. Most of them function as centers of religious education.
} 
education, acquisition of the Quran knowledge and learning Arabic was justified for them, and also culturally important to such a degree that they did not consider it necessary to educate children in state schools.

A similar situation occurred in Tibet in 1990s, where parents massively resigned from state education to the benefit of education in or at monasteries. The arguments in favour of education outside the state school system included better learning conditions in monasteries; learning written and spoken Tibetan (and consequently strengthening the sense of own identity); learning general human rules or general knowledge of science. Another cause of sending children to monasteries was poverty. Parents who could not secure decent life of their children (and bear the costs of traditional education), sent them to be taught at cheaper monasteries (also paid, but justified in spiritual sense). The child/student in a monastery means a social advancement for the family and better life for the offspring (Bass, 1998). It is reasonable to refer once again to the studies of Mackerras (1998) here, in which he notices that the rebirth of education in the religious spirit is related to dissemination of the state education. It is a kind of "social rebellion" of minzu against the total secularisation of schools.

The total ban on teaching religion in state schools has brought about negative social consequences in China. Gladney's studies (1999) regarding the level of knowledge about the religious dogmas of Islam among the Chinese demonstrated that the lack of religious education in schools results in very low social knowledge about Islam, particularly among the Han people. According to the researcher, majority of the society (i.e. the Han people), who never crossed the mosque door and does not have basic knowledge about Islam adheres to the common knowledge about Islam in China and Muslim identity (Gladney, 1999: 58). I would like to add that there are various representations of this religion; certainly different from its understanding in the popular culture, created to a large degree by the media. The Muslims in China have a very rich cultural, religious and school tradition, which affected the development of Chinese culture and society. Postiglione (1998) states that the state school additionally marginalises the school Muslim minority and puts it in an unfavourable light. It is a common practice to use low results of the Muslim minority learning and present them to prove their failure, particularly if the results are compared with the results of students from Tatar or Uzbek minority (Postiglione, 1998).

The examples above demonstrate that particularly the religious minorities, by means of organised religious centres, do their best to maintain the religious identity of minzu unchanged. It might be said that the abovementioned expansion of the totally secularised state education make the minority groups feel an even stronger 
need to affirm their identity. It is worthwhile to refer here to the studies of Baden Nima (1997), who on the example of the Tibet society demonstrates that the cause to quit school by the minority might be psychological. Nima noticed that some children, who did not find references to their own religion, history and language in educational materials, irreversibly lost motivation to learning, and lost their interest in school as such (Nima, 1997). I would like to add that it is a characteristic feature of the Chinese school enrolment rate at the domestic level to give up school during subsequent phases of the educational process. Postiglione (1998) indicates that most students drop out of primary school, however it is much less frequent in first and second-degree middle education. The problem of dropping out of school exists in entire China, however it is the most serious issue in Tibet. The key importance for the level of education in China is the economy of this region. As Bass underlines, the level of education is higher in regions with well-developed industrial infrastructure and in places where financial outlays for education are higher (Bass, 1998). According to statistics, the investment of China in education is low; the lowest among intensively developing countries. Most countries spend approx. $5 \%$ of their GDP for education. In the last 10 years, China (except for Hong Kong), on average has spent approximately $2.23 \%$ of its GDP on education (cf. UNESCO reports).

\section{How to say "school" in chinese in tibet?}

Examples from all around the world demonstrate that each country creates its language policy in accordance with domestic conditions. In Switzerland we have a few official languages, in Finland there are two, in the USA one, whereas is India the system of lingua franca was worked out. In the recent decades, the minority rights, including the use of their own language, have been more emphasised, and the examples such as the Chinese one demonstrate that in a deeply diversified society it is hard to implement a solution according to its multicultural nature.

In China, the right of the minorities to use their own languages, not only in schools but also in everyday life, is a field of tension in many disputes and discussions concerning respecting the minority rights. In 1950s, following the decree of the Chinese government, the linguistic groups were divided and officially differentiated, but it needs to be emphasised that the range and nature of languages, and their dialectic diversity in areas populated by minzu has still not been fully discovered. It should also be mentioned that it is additionally complicated due to political, legal and administrative reasons. 
Maria Kurpaska in the book Chinese Language(s): A Look through the Prism of The Great Dictionary of Modern Chinese Dialects (Trends in Linguistics: Studies and Monographs) made a detailed analysis of the Chinese linguistic monolith. Referring to the researchers such as Zhou Qingsheng, Li Rong or Dao Bu she states that in China there are over 80 languages (dialects). A simplified analysis of the language situation in China needs to be presented in order to demonstrate the range of the problem. In China, then, three main language groups can be differentiated: (1) Mandarin Chinese ${ }^{6}$ (putonghua, guoyu) - dominating among the Han and Hui people as well as Manchus, (2) languages of minority groups, using their own written and spoken language, i.e. Mongols, Tibetans, Uyghurs, Kazakhs, Koreans, Russians, Yi, Lahu, Kachins, Xibe, (3) the remaining groups using only the spoken language, without the written one (Kurpaska, 2010). As Rui Yang and Mei Wu (2009) state, in accordance with the Constitution of the People's Republic of China and the Resolution on Education, the defined minorities are fully entitled to use and develop their own language.

According to Zhao Zhenzhou (2014), in China there are two types of language teaching for the minorities. In the first option the minzu students can follow the normal curriculum with the minority of Han (minkaohan): they go to the same class, where the language of instruction is the official language and all the students take the same exams. Additionally, there is a foreign language, as an extracurricular subject. The minzu students following this educational path are given additional points during the recruitment to the second-degree middle school. The second kind of language education for minzu consists of specially constructed teaching curricula for ethnic minorities (minkaomin), containing the curriculum in two languages (in the official national language and the language of minority) and optionally a foreign language. This kind of education differs from the bilingual European schooling. The Chinese bilingual schooling has been interpreted and adjusted to the political conditions and possibilities. In China, similarly to other multilingual countries, the bulk of the teaching personnel is subjected to the state education system and educational materials go through the system of official acceptance by the state. It is worth adding that educational and teaching materials in the minkaomin schooling are often translated from the official national language, therefore minzu students receive a Chinese handbook in a language of the minority. This type of education is available from the kindergarten to the middle school. The transition from one type of schooling

${ }^{6}$ The term "Mandarin" originates from the ancient European name of a Chinese bureaucratmandarin. In Chinese, Mandarin languages are referred to as guānhuà, which means "the speech of officials," and in popular language as běifānghuà "Northern dialect." 
(minkaohan) to the other (minkaomin) is difficult and happens very rarely. The minzu students most frequently make a "rational" choice, which makes it more likely to be accepted to the middle school and opt for the first-type schooling, simultaneously sacrificing learning in the minzu language and culture (Zhenzhou, 2014).

In China there are also areas independent culturally, and to some degree also politically, such as Tibet, where students are offered as many as seven models of bilingual teaching in the minkaomin system. The models were described in detail by Zhang Tingfang ${ }^{7}$, and according to the annual studies, despite so many solutions, 95\% of primary school students follow the model in which the official language is the language of instruction in all subjects, apart from the lessons of Tibetan (Rong, 2014). A certain trend is visible here: the teaching model is shifting away from the model in Tibetan towards the official language, particularly when the student intends to continue learning in the second-degree middle school. This way the choice becomes illusive and becomes a necessity for students who want to continue learning, for instance in the second-degree middle school. Regie Stites, quoting Xing Gongwan (1999), directly characterises teaching the Mandarin Chinese as the "system of dominance," directed against the minorities. The researcher straightforwardly claims that the linguistic Tower of Babel in China and the lack of applicable solutions is one of the barriers in popularising education as such (Stites, 1999).

Chinese researchers, however, state that learning in the official language is necessary and indispensable. Ma Rong (2014) writes that in the case of minzu students, learning Mandarin Chinese is as important as learning the minzu language and growing up in the minzu culture. The author writes, "Students from minorities should learn in their mother tongue in order to inherit their traditional culture. The knowledge of Mandarin Chinese is necessary to maintain internal communication and to participate in national, social and economic development. Simultaneously, Han students should have the opportunity to study the language and culture of minorities, which will help the national unity of China and will also allow maintaining and supporting cultural diversity" (Rong, 2014:84). The researcher notices the need of multicultural education and sees in it a cure for Chinese linguistic turmoil. Moreover, he underlines that in the light of the changing Chinese job market and mass internal migrations, there is the need of education in the national language, in order to allow the school graduates to function professionally.

${ }^{7}$ Ma Rong refers to the study by Zhang Tingfang titled Situation and Studies of Putonghua Teaching among Minorities in Tibet. 
Therefore, the popularisation of Mandarin Chinese is also additionally enhanced by neoliberal market reforms. Two factors play a significant role here: free flow of workforce and mass internal migrations for professional purposes, which fuel the requirement for the national language.

The Chinese example demonstrates that bilingual education in further perspective could be an opportunity for minorities and it could affect positively the functioning of minzu. Nonetheless, an important question remains, which model of bilingual education should be chosen, how much place should be left for individual practices and how deeply the country can interfere in the contents of minority education. It might be claimed, therefore, that a significant issue for bilingual education in China is the pressure on learning Mandarin and simultaneous claims that minorities are fully entitled to develop and use their own languages. The applied educational practices are contrary to the multicultural model of teaching and a clear transition towards the assimilation model.

\section{Conclusion}

To conclude and summarise, interesting remarks of Iris Marion Young (1998) are worth reminding. The researcher finds out that the Chinese problem of minorities is a materialisation of the "dilemma of differences," based on the fact that disadvantaged and oppressed groups are forced to deny the existence of differences instead of inclusion in institutions (also educational). They also have to maintain differences to allow their compensation (Young, 1998). This dilemma is additionally complicated by the fact that China controls and manages these processes. Chinese authorities formally establish the differences between minzu and simultaneously allow the entities to deny the social unity. It might be said that this kind of communal approach to citizenship somehow forces minzu to protect their own culture and identity. Double affiliation, to the culture of minority and culture of the entire society, and resulting double duties are a source of conflicts and failures. To solve the problem, the state proposes, for instance, a "liberal" solution, where the minzu community can "enjoy" personal freedom while choosing the type of language education or allows existence of religious education in mosques and monasteries, where the choice is illusive, and common cultural dominance of Han people is very clear.

The Chinese problem results from the fact that the school system is highly centralised, culturally deeply immersed in Chinese, state framework and must face colossal regional differences, which are reflected in a diversified economic devel- 
opment, in deeply adverse cultures and various languages and religions. In view of the above, China faces a serious challenge, in which it is necessary to study the educational curriculum and focus activities on the construction of open and fair society.

\section{Bibliography}

Albert E. (2018). Religion in China, https://www.cfr.org/backgrounder/religion-china, access on 29.04.2019.

Bass C. (1998). Education in Tibet: Policy and Practice since 1950 (Politics in Contemporary Asia). London.

Gladney D.C. (1996). Muslim Chinese: Ethnic Nationalism in the People's Republic. London and Cambridge.

Gladney D.C. (1999). Making Muslim in China: Education, Islamization and Representation [in:] G. A. Postiglione (eds.). China's National Minority Education. Culture, schooling and development. New York and London, pp. 55-94.

He B. (1998). Can Kymlicka's Liberal Theory of Minority Rights be Applied in East Asia? [in:] P. van der Velde and A.McKay (eds.). New Developments in Asian Studies. London and New York, pp. 20-44.

The Constitution of the People's Republic of China of 14 March 2004 (Chapter II, art. 36), http://www. npc.gov.cn/englishnpc/Constitution/2007-11/15/content_1372964.htm, access on 01.08.2016.

Kurpaska M. (2010). Chinese language(s): a look through the prism of The Great dictionary of modern Chinese dialects. Berlin/New York.

Leibold J. (2013). Ethnic Policy in China: Is Reform Inevitable? "Policy Studies" East-West Center, no 68.

Leibold J., Yangbin Ch. (2014). Introduction: Minority Education in China Minority Education in China: Balancing Unity and Diversity in an Era of Critical Pluralism [in:] J. Leibold, Ch. Yangbin (eds.). Minority Education in China, Balancing unity and diversity in era of critical pluralism. Hong Kong, pp. 1-24.

Mackerras C. (1999). Religion and the Education of China's Minorities [in:] G. A. Postiglione (eds.). China's National Minority Education. Culture, schooling and development. New York and London, pp. 23-53.

Mańkowska A. (2018). Linguistic educational reality in multicultural China. Unity or diversity? (Językowa rzeczywistość edukacyjna w wielokulturowych Chinach. Jedność czy różnorodność?) "Pedagogika Szkoły Wyższej," 2018, 2/2017 (22), pp. 121-132, DOI: 10.18276/psw.2017.2-11

Nima B. (1997). The way out for Tibetan education. "Chinese Education \& Society," 30 (4), pp. 7-20.

Postiglione G.A. (1998). State Schooling and Ethnicity in China: The Rise or Demise of Multiculturalism? http://files.eric.ed.gov/fulltext/ED427100.pdf, access on 12.08.2015.

Rong M. (2014). Bilingual education and language policy in Tibet [in:] J. Leibold, Ch. Yangbin (eds.). Minority Education in China, Balancing unity and diversity in era of critical pluralism. Hong Kong, pp. 83-106.

Smith W. (2009). China's Tibet? Autonomy or assimilation? New York. 
Stites R. (1999). Writing cultural boundaries, National minority language policy, literacy planning and bilingual education [in:] G. A. Postiglione (eds.). China's national minority education: Culture, schooling, and development. New York, pp. 95-130.

Unesco, Expenditure on education as \% of GDP (from government sources), http://data.uis.unesco.org/ Index.aspx?DataSetCode=EDULIT_DS\&popupcustomise=true\&lang=en, access on 01.08.2015.

Young I.M. (1998). Polity and Group Difference: A Critique of the Ideal of Universal Citizenship [in:] G. Shafir (eds.). The Citizenship Debates: A Reader. Minneapolis-Londyn. pp. 263-291.

Young R., Wu M. (2009). Education for ethnic minorities in China: a policy critique. "Special Edition on Education and Ethnicity," Volume 6, Number 2, pp. 117-131.

Zhenzhou Z. (2014). The trilingual Trap [in:] J. Leibold, Ch. Yangbin (eds.). Minority Education in China, Balancing unity and diversity in era of critical pluralism. Hong Kong, pp. 239-258. 